\title{
Supercritical Carbon Dioxide-A Powerful Tool for Green Biomaterial Chemistry
}

\author{
N. N. Veryasova ${ }^{a, *}$, A. E. Lazhko ${ }^{b}$, D. E. Isaev ${ }^{a}$, E. A. Grebenik ${ }^{a}$, and P. S. Timashev ${ }^{a, b, c}$ \\ ${ }^{a}$ Institute for Regenerative Medicine, Sechenov First Moscow State Medical University, Moscow, 119991 Russia \\ ${ }^{b}$ Institute of Photonic Technologies, Research Center “Crystallography and Photonics,” Russian Academy of Sciences, \\ Troitsk, Moscow, 108840 Russia \\ c Semenov Institute of Chemical Physics, Russian Academy of Sciences, Moscow, 119991 Russia \\ *e-mail: veryasova.nadezhda@gmail.com \\ Received August 1, 2018; revised August 10, 2018; accepted August 10, 2018
}

\begin{abstract}
The key aspects of the modification of biocompatible materials in a medium of supercritical carbon dioxide $\left(\mathrm{SC}-\mathrm{CO}_{2}\right)$ and the main trends in the application of the described method to the fabrication of threedimensional scaffolds, sterilization of medical devices, decellularization of mammalian tissues, and impregnation of materials with biologically active molecules are described. Due to the nondestructive action of the medium of $\mathrm{SC}-\mathrm{CO}_{2}$ on the architectonics of an extracellular matrix, the preservation of the mechanical properties and structure of the materials being treated, and an absence of the need for the postprocessing and purification of the formed matrices, the presented method can be considered as a versatile approach to the solution of urgent problems in biomedical materials science.
\end{abstract}

Keywords: supercritical carbon dioxide, biomaterials, sterilization, decellularization, impregnation, tissue engineering

DOI: $10.1134 / \mathrm{S} 1990793119070236$

\section{INTRODUCTION}

The requirements to the conditions of processing of biocompatible materials often exclude the use of classical methods involving aggressive action on the material (e.g., high-temperature treatment). As an alternative, researchers resort to new processing technologies and approaches focusing on the direction of "Green Chemistry" in the first place. A medium of supercritical carbon dioxide $\left(\mathrm{SC}-\mathrm{CO}_{2}\right)$ possesses unique advantages that can be used for the preparation of biocompatible materials simultaneously decreasing their cost price. First of all, this refers to the possibility of conducting processes at low temperatures, which provides the opportunity to work with biopolymers and thermally sensitive components such as collagen [1] and gels on the basis of alginate, gellan gum, chitosan, and an extracellular matrix [2-5]. Low surface tension promotes the penetration of $\mathrm{SC}-\mathrm{CO}_{2}$ into solid and colloidal structures, which makes it possible to efficiently sterilize medical devices with the preservation of the structure and physicochemical properties, as was shown in the example of hydrogels $[6,7]$ and an extracellular matrix $[8,9]$. The ability of $\mathrm{SC}-\mathrm{CO}_{2}$ to solubilize nonpolar and weekly polar molecules found its reflection in the impregnation of biomaterials with various active components (antibiotics, anti-inflammatory agents, etc.) as well as in decellularization, i.e., removal of cellular components from a tissue for the purpose of obtaining the extracellular matrix. Reviews [10-13] have been devoted to the problems of preparation and sterilization of biomaterials in a medium of $\mathrm{SC}-\mathrm{CO}_{2}$.

The presented review summarizes the experimental results concerning the application of a medium of $\mathrm{SC}-\mathrm{CO}_{2}$ for the preparation of biomaterials and fabrication of medical devices. The considered aspects schematically depicted in Fig. 1 reflect the scientific content of the presented review. Initial materials such as mammalian tissues, three-dimensional scaffolds or medical devices, polymers, and biomaterials for reconstructive surgery are specified on the left. As a result of processing in a medium of $\mathrm{SC}-\mathrm{CO}_{2}$ at certain temperature $(T)$ and pressure $(P)$, the materials are subjected to the corresponding modifications that are aimed at changing the composition (impregnation), extraction of eukaryotic cells (decellularization) and microorganisms (sterilization), and structuring (foaming). The products of processing in an $\mathrm{SC}-\mathrm{CO}_{2}$ medium are shown on the right.

The first direction is devoted to the impregnation of a series of biomaterials with biologically active components for the preparation of wound dressings, stents, and three-dimensional matrices with gradual release of a drug for prolonged and local action. Further, the 


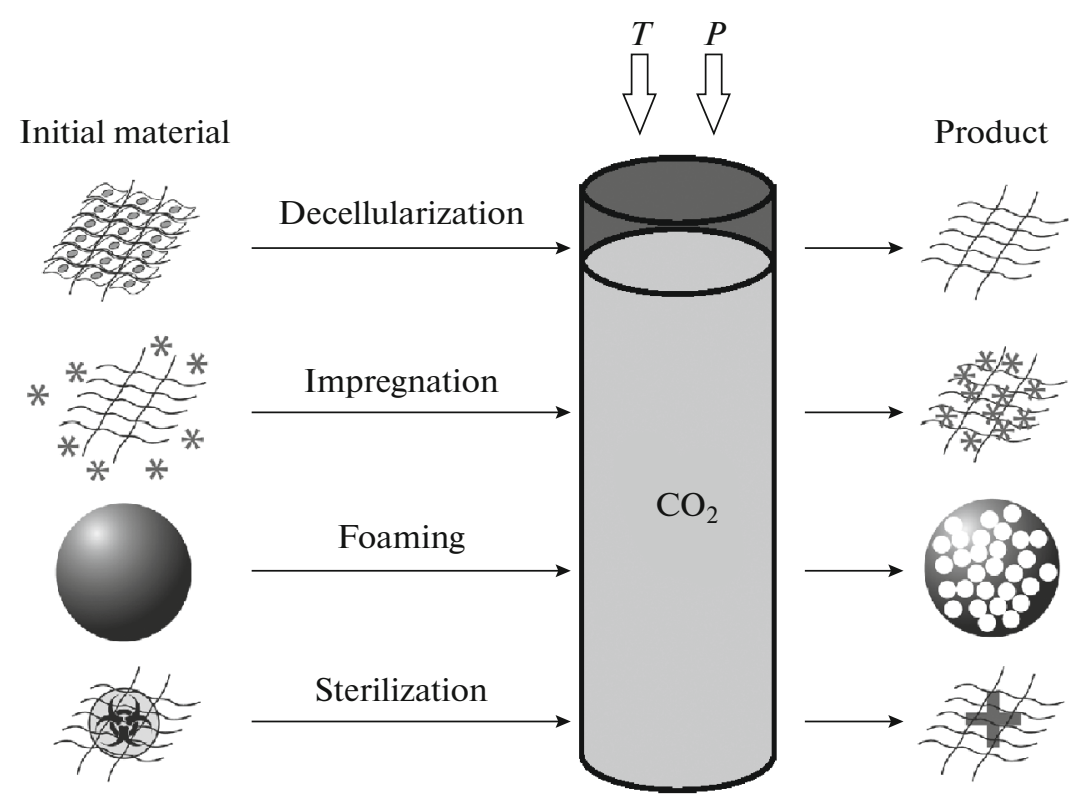

Fig. 1. The application of a medium of $\mathrm{SC}-\mathrm{CO}_{2}$ for the formation of biomaterials.

review presents the research in the field of formation of three-dimensional matrices on the basis of polymers, bioceramics, and biologically active glass via foaming in a medium of $\mathrm{SC}-\mathrm{CO}_{2}$ for the tasks of reconstructive surgery. Below, examples of sterilization of medical devices and tissue-engineered scaffolds using $\mathrm{SC}-\mathrm{CO}_{2}$ are considered in detail, and the influence of the medium on the mechanical and structural properties of the materials being obtained is discussed. The review is finalized by the analysis of the research on the decellularization of tissues via processing in $\mathrm{SC}-\mathrm{CO}_{2}$, i.e., materials on the basis of cell-free extracellular matrix proteins.

\section{IMPREGNATION OF POLYMERS IN A MEDIUM OF SC- $\mathrm{CO}_{2}$}

The impregnation of biocompatible materials and medical devices in a medium of $\mathrm{SC}-\mathrm{CO}_{2}$ can be used instead of traditional methods such as extrusion [14], surface overlaying [15], and soaking in a solution [16]. The use of an $\mathrm{SC}-\mathrm{CO}_{2}$ medium makes it possible to impregnate a biomaterial with an active component avoiding heating and a long-term step of removal of organic solvents. Thus, e.g., Dias et al. developed a wound dressing on the basis of a derivative of chitosan impregnated with anti-inflammatory and antimicrobial flavonoids (quercetin and thymol) [17]. In another work, Pascoal et al. impregnated commercial wound dressings on the basis of gelatin and a cellulose-collagen composite with copaiba oil for the treatment of cutaneous leishmaniasis [18]. Impregnation of a biodegradable double J-shaped urethral stent on the basis of alginate and gellan gum with ketoprofen was performed to decrease inflammatory response [2]. Ketoprofen is a nonsteroidal anti-inflammatory drug that is used to eliminate pain syndrome after surgical intervention. The authors of this work impregnated stents with ketoprofen in a medium of $\mathrm{SC}-\mathrm{CO}_{2}$. The highest degree of saturation with the drug was achieved at $40^{\circ} \mathrm{C}$, and it was $8.74 \mathrm{wt} \%$ in an alginate gel and $16.64 \mathrm{wt} \%$ in gellan gum. This difference in the degree of impregnation is determined by the different affinities of the materials of the stent to ketoprofen which is associated with a large amount of hydroxyl groups in gellan gum. In vitro tests showed that the release of the drug occurs within $72 \mathrm{~h}$, which conforms to the time required for the elimination of pain syndrome [2]. It was also proposed to impregnate an alginate biodegradable stent with anticancer drugs to fight urothelial cancer of the upper urinary tract [3]. It was shown that the time of release of drugs from the biodegradable matrix is threefold greater (up to $72 \mathrm{~h}$ ) in comparison with a polymer stent, which can promote the enhancement of the efficiency of the treatment.

Therefore, impregnation in an $\mathrm{SC}-\mathrm{CO}_{2}$ medium makes it possible to preserve the structure of the matrices and ready-to-use medical devices as well as using chemically unstable and thermally labile compounds for additional functionalization of the material. The high penetration capacity of $\mathrm{SC}-\mathrm{CO}_{2}$ determines efficient mass transfer, due to which the use of high temperatures and organic solvents which are used in molecular imprinting and soaking in a solvent, respectively, can be left behind. Currently, the impregnation of biomaterials and medical devices with drugs of different groups, such as antibiotics (ciprofloxacin [19]), anti-inflammatory drugs (dexamethasone [19], 
ibuprofen [20], ketoprofen [21], and indomethacin [22]), and beta-adrenoblockers (timolol [23]) has been successfully performed. As is described above, the properties of $\mathrm{SC}-\mathrm{CO}_{2}$ open up potential opportunities for the development of materials reducing the inflammatory response to implantation due to the local release of medicinal components from a polymer matrix.

\section{FORMATION OF THREE-DIMENSIONAL MATRICES IN A MEDIUM OF SC- $\mathrm{CO}_{2}$}

In early 2000 s, a new direction has emerged in materials science, associated with the development of biomaterials for tissue engineering. Three-dimensional matrices are populated with cells and functionalized with biologically active molecules, forming a tissue bioequivalent that can stimulate regeneration processes when implanted to a damaged site. In the field of development of biomaterials, foaming in a $\mathrm{SC}-\mathrm{CO}_{2}$ is applied for the formation of three-dimensional matrices. The use of a medium of $\mathrm{SC}-\mathrm{CO}_{2}$ makes it possible to form a material with defined size and pore morphology without using toxic solvents. Thus, porous $3 \mathrm{D}$ structures with a pore size from 150 to $340 \mu \mathrm{m}$ and a porosity of about $70 \%$ were fabricated using impregnation of polycaprolactone with a plantbased antibacterial component in the process of foaming in $\mathrm{SC}-\mathrm{CO}_{2}$ [24]. The authors of the work used a closed system, in which the processes of extraction of the active component from the plant feedstock and foaming occurred in one closed cycle, which is of interest for scaling up the manufacturing process of tissue-engineered matrices. However, the chemical nature of the substance should be considered when fabricating matrices via foaming in $\mathrm{SC}-\mathrm{CO}_{2}$. For example, the authors of [25] subjected a material made with arabinoxylan (a component of hemicellulose), modified by poly(ethylene glycol) (PEG) with different molecular weights, to foaming. The obtained materials possessed different degrees of porosity. The authors explained this effect by the interaction of PEG molecules with $\mathrm{SC}-\mathrm{CO}_{2}$, which reflects upon the number of nucleation centers in the bulk of the material.

The research in the field of development of matrices for the reconstruction of bone tissue also involves supercritical fluid technologies. Foaming in a medium of $\mathrm{SC}-\mathrm{CO}_{2}$ makes it possible to form a porous structure for fragile materials, such as biologically active glass, hydroxyapatite, and various composites on the basis of hydroxyapatite with polymers. The authors of $[26,27]$ tested three-dimensional matrices obtained from the combination of hydroxyapatite and polylactide for the development of a bioequivalent of bone tissue. The optimum indices of porosity and mechanical properties were achieved at a weight ratio of polylactide and hydroxyapatite of $8: 2$ [28]. To obtain a matrix, a mechanical mixture of the components was placed into a reactor, after which it was saturated with $\mathrm{SC}-\mathrm{CO}_{2}$ for $30 \mathrm{~min}$ at $20 \mathrm{MPa}$ and $37^{\circ} \mathrm{C}$, and then the pressure was reduced at a rate of $5 \mathrm{MPa} / \mathrm{min}$. Despite the fact that the rigidity and Young modulus of the obtained material were lower than the cortical plate, the authors suppose that the material can be in demand as a bone-substituting filler [28]. Antonov et al. [29] structured a mixture of polylactide and nanosized hydroxyapatite at the same weight ratio $(20 \%$ hydroxyapatite) via surface-selective laser sintering in a medium of $\mathrm{SC}-\mathrm{CO}_{2}$. Surface-selective laser sintering makes it possible to form three-dimensional scaffolds on the basis of computational models, which is promising for the tasks of personalized medicine. However, this method cannot be applied for a polylactide-hydroxyapatite physical mixture because hydroxyapatite particles do not undergo sintering and to prevent the sintering of polylactide particles. In this connection, a mixture of the components was exposed for $1 \mathrm{~h}$ at $10 \mathrm{MPa}$ and $40^{\circ} \mathrm{C}$ in a medium of $\mathrm{SC}-\mathrm{CO}_{2}$. The obtained monolith was ground, and fractions with a size of $100-200 \mu \mathrm{m}$ were subjected to selective laser sintering. The ultimate flexural strength of the specimens corresponded to the values for the specimens made of polylactide, which is indicative of the introduction of hydroxyapatite nanoparticles into the composition of the polymer during its plasticization in a medium of $\mathrm{SC}-\mathrm{CO}_{2}[29,30]$.

Diaz-Gomez et al. obtained three-dimensional scaffolds on the basis of a mixture of polycaprolactone, hydroxyapatite, and silk fibroin via foaming in a medium of $\mathrm{SC}-\mathrm{CO}_{2}$ [31]. The authors showed that fibroin intensifies the osteoinductive properties of hydroxyapatite, thus forming a friendly environment for the osteodifferentiation of MC3T3 mouse osteoblastic progenitor cells. This effect was confirmed by the higher degree of mineralization of implants in vitro and in vivo in comparison with the specimens containing only polycaprolactone and hydroxyapatite. The Young modulus of the obtained material corresponded to the data for the cortical plate which makes the material suitable for the reconstruction of bone tissue.

In [32], precipitation in $\mathrm{SC}-\mathrm{CO}_{2}$, which served as a supercritical antisolvent, was used for the preparation of matrices. The authors obtained fibrous anisotropic structures from poly(methyl methacrylate), L-polylactide, polycaprolactone, and a mixture of polycaprolactone and poly(methyl methacrylate). The authors selected processing conditions, under which the polymers form fibers with a rough surface combined into three-dimensional networks with a specific surface area of $100-400 \mathrm{~m}^{2} / \mathrm{g}$. In another work, the biocompatibility of three-dimensional scaffolds on the basis of copolymers of $\varepsilon$-caprolactone and $\mathrm{D}$, L-lactide obtained via foaming in a medium of $\mathrm{SC}-\mathrm{CO}_{2}$ was shown [33].

The diversity of approaches (the use of an $\mathrm{SC}-\mathrm{CO}_{2}-$ water emulsion and phase inversion in a medium of $\mathrm{SC}-\mathrm{CO}_{2}$ ) [34] and possibility for varying conditions 
make this medium suitable for the development of three-dimensional scaffolds with a defined morphology for various tasks. By tuning the parameters of $\mathrm{SC}-\mathrm{CO}_{2}$ for each task, it is possible to govern the rate of the changes occurring in the layers of a material upon a decrease in pressure and the structural parameters of the matrix being obtained. Characteristic features such as nontoxicity, low process temperatures, and simplicity of variation of the properties of SC$\mathrm{CO}_{2}$ distinguish the process of formation of porous materials from traditional methods such as leaching and lyophilization and make it possible to use it for the creation of biocompatible materials.

\section{STERILIZATION IN A MEDIUM OF SC- $\mathrm{CO}_{2}$}

A medium of $\mathrm{SC}-\mathrm{CO}_{2}$ has been in widespread use for the extraction of organic substances from naturally occurring feedstock (e.g., extraction of caffeine from coffee beans) since the early 1980s. By varying temperature and/or pressure, one can govern the extracting properties of this fluid which determines the relevance of this extraction method. The extracting capacity of this method has generated interest in $\mathrm{SC}-\mathrm{CO}_{2}$ as a tool for the sterilization of biomaterials. NovaSterilis, which has developed a technology of sterilization of medical devices using a medium of $\mathrm{SC}-\mathrm{CO}_{2}$, was founded in 2001 in the United States. The Nova2200 unit has entered the market since 2007. The processing of biomaterials according to the technology of NovaSterilis anticipates the use of a NovaKill trademark additive that contains a mixture of peracetic acid and hydrogen peroxide. The working concentrations of peracetic acid and hydrogen peroxide in the reactor chamber do not exceed 0.002 and $0.0006 \%$, respectively, which makes it possible to decrease the concentration of peracetic acid 150-fold in comparison with a standard sterilization protocol [35]. The technology guarantees the achievement of a level of sterility which corresponds to the standards for medical devices (ISO 11137-2-2011). Over 10 years, the enterprise released three models of sterilization units and announced the release of a series of units for laboratory needs in late 2018.

The first work proving the efficiency of the technology was devoted to the sterilization of palm fiber after oil expression [36]. It was shown that processing in a medium of $\mathrm{SC}-\mathrm{CO}_{2}$ at $40^{\circ} \mathrm{C}$ and $20.5 \mathrm{MPa}$ for 60 min leads to the complete eradication of Gramnegative bacteria (Bacillus). The joint action of $\mathrm{SC}-\mathrm{CO}_{2}$ and peracetic acid leads to the eradication of viruses, bacteria and their spores, and molds which was demonstrated by the example of the extracellular matrix of porcine derma [37]. The sterilization was performed at $35-41^{\circ} \mathrm{C}$ and $13.65-14.55 \mathrm{MPa}$. SC $-\mathrm{CO}_{2}$ accelerates the process of penetration of peracetic acid into microorganisms and, hence, delivery of oxygen and free radicals, which makes it possible to shorten the time of processing of the material as well as to decrease the concentration of peracetic acid (from 1000 to $55 \mathrm{ppm})$. However, processing in $\mathrm{SC}-\mathrm{CO}_{2}$ leads to an insignificant change in the mechanical properties of the material, which can be induced by the change in the structure of collagen of the extracellular matrix and influence on the properties of the matrix in vivo.

Nevertheless, the technology of sterilization in a medium of $\mathrm{SC}-\mathrm{CO}_{2}$ is superior to traditional sterilization by gamma irradiation in terms of the preservation of the native properties as it was shown by the example of sterilization of allografts of ligaments and tendons. The procedure of sterilization of tibial tendons and a medial meniscus in a medium of $\mathrm{SC}-\mathrm{CO}_{2}$ to a lesser extent impacted the biomechanical properties of tendons in comparison with the standard procedure of sterilization by gamma irradiation [38, 39]. The results of morphological analysis confirmed better preservation of the structure of the tissue after processing in $\mathrm{SC}-\mathrm{CO}_{2}[39]$. In addition, it was shown by Yanke that the sterilization of human patellar tendons by gamma irradiation with a dose of $1.0-1.2 \mathrm{mrad}$ decreases the rigidity of the material by $20 \%$. It is noteworthy that the inactivation of HIV requires a dose of 1.5$4.0 \mathrm{mrad}[40]$.

A similar trend was noted for decellularized lung tissue [9]. Sterilization in a medium of $\mathrm{SC}-\mathrm{CO}_{2}$ did not violate the native architecture of the tissue and preserved the key components in the composition of the extracellular matrix (elastin, desmosine, and collagen). Processing in $\mathrm{SC}-\mathrm{CO}_{2}$ increased the rigidity of the tissue; however, the authors observed significant changes only in the region of nonphysiologic stresses. Moreover, the mechanical properties and structure of the tissue were also preserved within six months after the processing in $\mathrm{SC}-\mathrm{CO}_{2}$. Here, the specimens sterilized by peracetic acid became fragile after 6 months of storage and stood lower stress in breaking strength tests. The loss of mechanical integrity of the tissue resulted from the degradation of the extracellular matrix under the action of the residual amounts of acetic acid.

For bone tissue transplants, the preservation of mechanical properties is also of primary importance. It has been shown that the procedure of sterilization in a medium of $\mathrm{SC}-\mathrm{CO}_{2}$ preserves the mechanical properties of bone allografts, which is the main advantage over gamma irradiation [41-43].

The preservation of the composition and structural organization of an extracellular matrix as a result of sterilization is the most sought after for complex threedimensional scaffolds consisting of connective tissues of various kinds such as cardiac valves. In vitro and in vivo studies showed that, in comparison with sterilization using traditional techniques (gamma irradiation, a mixture of ethanol with peracetic acid, electrolyzed water, and in a solution of hydrogen peroxide), steril- 
ization in a medium of $\mathrm{SC}-\mathrm{CO}_{2}$ has the most sparing effect on the transplants of porcine aortic valves without substantially affecting their mechanical and structural properties and, as a result, functional qualities $[44,45]$.

Sterilization in a medium of $\mathrm{SC}-\mathrm{CO}_{2}$ is also applicable to hydrogels on the basis of alginate and collagen; it does not affect their composition, mechanical properties, and affinity of cells [7] as opposed to vapor sterilization [46]. Sterilization by UV irradiation preserves the mechanical properties of an alginate gel; however, it does not completely kill bacteria at thicknesses of $1 \mathrm{~mm}$ or greater [46, 47].

It has been shown $[48,49]$ using the example of inactivation of Gram-negative bacteria $E$. coli that the ability to inactivate bacteria is inherent in $\mathrm{SC}-\mathrm{CO}_{2}$ but is not characteristic for nitrogen or oxygen in the supercritical state. The authors hypothesize that the death of bacteria in a humid environment after the action of $\mathrm{SC}-\mathrm{CO}_{2}$ is associated with a decrease in $\mathrm{pH}$ inside a cell due to the formation of carbonic acid. Therefore, processing in a medium of $\mathrm{SC}-\mathrm{CO}_{2}$ is an efficient method for the sterilization of biomaterials with different natures, compositions, structures, and mechanical properties. Low surface tension and high density allows $\mathrm{SC}-\mathrm{CO}_{2}$ to efficiently penetrate into solid matrices and extract microorganisms, and the low temperature of the process and absence of toxic chemical agents make this method suitable for most biomaterials, including hydrogels and complex threedimensional scaffolds.

\section{DECELLULARIZATION OF MAMMALIAN TISSUES IN A MEDIUM OF SC- $\mathrm{CO}_{2}$}

The extractive properties of $\mathrm{SC}-\mathrm{CO}_{2}$ determine successful application of the technology for the decellularization of mammalian tissues. Decellularization is required for the elimination of the immunogenicity of the tissues of xenogeneic and allogenic origin. The process of decellularization is the processing of a tissue for the purpose of removing cells and antigens from the material. The material formed as a result of this process is the extracellular matrix consisting of proteins (collagen, laminin, and elastin), proteoglycans, and glycoproteins, as well as essential growth factors, angiogenesis factors, and others [50]. The obtained matrix serves as the base for tissue-engineered structures intended for a wide range of applications because the composition of the extracellular matrix is the most close to the natural environment of cells and stimulates the regeneration of damaged tissues. Currently, there are a lot of methods of decellularization of tissues including treatment by detergents (sodium dodecyl sulfate (SDS), sodium deoxycholate, Triton $\mathrm{X}-100$, etc.), enzymes (trypsin, deoxyribonuclease (DNase), and ribonuclease (RNase)), and an alkali as well as cyclic freezing-thawing and high-pressure action (up to $1 \mathrm{GPa}$ ) [50]. These techniques require time costs as well as long-term rinsing of the material from the residual quantities of the reagents. Despite the existence of a wide variety of decellularization protocols, there is a need for the thorough selection of parameters, which is determined by several reasons. On the one hand, this procedure is intended for removing the residues of the cell material of the donor, antigens, and potential pathogens. On the other hand, it is important to provide the preservation of the structural organization of an extracellular matrix with the set of functions inherent in it. In this connection, the optimization of these methods and the search for new solutions are still ongoing. The technology of decellularization in a medium of $\mathrm{SC}-\mathrm{CO}_{2}$ is attracting increasing attention, in particular, due to the ability to solubilize polar molecules and possibility for varying the strength of the solvent by means of changing temperature and/or pressure.

In 2008, a first attempt at the decellularization of porcine aorta in a medium of $\mathrm{SC}-\mathrm{CO}_{2}$ with the addition of absolute ethanol was undertaken [51]. A morphological analysis showed that the addition of ethanol promotes the extraction of the cell material (nuclei and phospholipids), which was unachievable in the case of the use of $\mathrm{SC}-\mathrm{CO}_{2}$ without additives. The authors recorded a decrease in the amount of phospholipids depending on the time of processing, pressure, and rate of venting in the reactor. When varying the conditions, the minimum residual amount of phospholipids was $20 \%$, which was achieved as a result of a 20 -min treatment at $15 \mathrm{MPa}$ and $37^{\circ} \mathrm{C}$. It was found that, in the course of the processing in a SC$\mathrm{CO}_{2}$-ethanol system, the material acquires rigidity, which reflects upon the character of the stress-strain diagrams. This is associated with the dehydration of the tissue because ethanol is hygroscopic and SC$\mathrm{CO}_{2}$ dissolves up to $0.5 \%$ water [52]. However, the authors evaluated these changes in mechanical properties as insignificant because the deviations are not functionally significant [51]. The described study is fundamental in the field of decellularization using $\mathrm{SC}-\mathrm{CO}_{2}$ but did was not continued for a long time, probably due to the rapid development of methods of decellularization using detergents, enzymes, and other physicochemical methods. Factors such as the development of new instrumentation, transition to green chemistry, and wide use of $\mathrm{SC}-\mathrm{CO}_{2}$ as a medium for the preparation of biomaterials renewed the interest of researchers in the problem of decellularization in this fluid.

The investigation of the process of decellularization of the aorta in a medium of $\mathrm{SC}-\mathrm{CO}_{2}$ was continued in 2017. The authors changed the procedure, namely, they used $70 \%$ ethanol and the processing was performed for $1 \mathrm{~h}$ at $37^{\circ} \mathrm{C}$ and 17.2 and $31 \mathrm{MPa}$ [53] in a medium of $\mathrm{SC}-\mathrm{CO}_{2}$. Histological studies and assay of the residual DNA showed that complete removal of 
the cell material from the tissue is achieved at $31 \mathrm{MPa}$. However, the results cannot be considered promising because the structure of the extracellular matrix of the aorta significantly changes at an elevated pressure, and the organization of the external and internal layers becomes violated. These violations are capable of inducing the development of embolism and aneurism in the case of implantation, which is a severe restriction for the clinical application of the obtained biomaterial. In turn, the violation of the structure can affect the mechanical properties of an extracellular matrix; however, the authors did not investigate these parameters.

In [4], the authors used absolute ethanol as the cosolvent. The study was aimed at the decellularization of cardiac tissues followed by the formation of a hydrogel on the basis of an extracellular matrix-a source of glycosaminoglycans, proteins, and growth factors-for the treatment of ischemic diseases. To achieve the maximum effect, the pressure was increased to $35 \mathrm{MPa}$, and the duration of the processing was lengthened to $6 \mathrm{~h}$. The obtained material was then rinsed in a solution of DNase I for 5 days. It was found that processing in a medium of $\mathrm{SC}-\mathrm{CO}_{2}$ better preserves the extracellular matrix components responsible for angiogenesis in comparison with processing in a $1 \%$ solution of SDS. The stimulation of angiogenesis was shown in vivo in the case of subcutaneous implantation of the hydrogel to mice. The extracellular matrix obtained from the $\mathrm{SC}-\mathrm{CO}_{2}$-treated tissues stimulated the formation of vessels to a significantly greater extent in comparison with the SDS group and control gel on the basis of type I collagen. Therefore, decellularization via extraction in a medium of SC$\mathrm{CO}_{2}$ opens up prospects for the development of bioinks for bioprinters and formation of three-dimensional structures on the basis of hydrogels.

In [54], Hashimoto et al. used $\mathrm{SC}-\mathrm{CO}_{2}$ for the decellularization of porcine cornea. The tissue was preliminarily subjected to osmotic shock by alternating $2 \mathrm{M} \mathrm{NaCl}$ solution and deionized water. Processing in a medium of $\mathrm{SC}-\mathrm{CO}_{2}$ was performed with the addition of $60 \%$ ethanol at $35 \mathrm{MPa}$ and $45^{\circ} \mathrm{C}$ for $80 \mathrm{~min}$. Such an approach made it possible to completely remove cellular components from the corneal tissue with the preservation of the appropriate optical properties of the material. However, the reduction of the amount of glycosaminoglycans and structural proteins in the course of the processing in $\mathrm{SC}-\mathrm{CO}_{2}$ led to the violation of the structural organization of the corneal extracellular matrix. When a traditional protocol based on the treatment by Triton X-100 was used, the effect was less pronounced. As was expected, the tissue decellularized in a medium of $\mathrm{SC}-\mathrm{CO}_{2}$ was inferior to the material treated by the detergent with respect to the indices of breaking strain (twofold) and Young modulus (threefold). Despite this, the results of the transplantation of the specimens from the $\mathrm{SC}-\mathrm{CO}_{2}$ group to rabbits gave the evidence of the fact that regeneration of the cornea occurs within two month; this was confirmed by the migration of keratocytes and corneal epithelial cells to the implant. No traces of rejection, inflammation, and vasifaction (which is impermissible for the cornea) were found. Six months after the transplantation, the cornea contained cells characteristic for a healthy tissue. In this study, the results of the regeneration of tissues with the use of transplants decellularized in a medium of $\mathrm{SC}-\mathrm{CO}_{2}$ over the long term were described for the first time. The physical method of decellularization of the cornea that was developed earlier consisted in the destruction of cells under the action of high pressure (up to $100 \mathrm{MPa}$ ) [54-56]. However, this method requires complex and expensive hardware.

Smolentsev et al. [57] formed a decellularized bone tissue matrix by means of extraction in a medium of $\mathrm{SC}-\mathrm{CO}_{2}$. Samples of a bovine cancellous bone were processed at $35 \mathrm{MPa}$ and $50^{\circ} \mathrm{C}$ for $30 \mathrm{~min}(25 \mathrm{~min}$ in a dynamic mode at a rate of the flow of $\mathrm{SC}-\mathrm{CO}_{2}$ of $16.9 \mathrm{~g} / \mathrm{min}$ and $5 \mathrm{~min}$ in a static mode). This stage was preceded by the treatment of the sample first in a $7 \%$ solution of $\mathrm{NaCl}$ for $12 \mathrm{~h}$ and then in a $0.1 \%$ solution of $\mathrm{H}_{2} \mathrm{O}_{2}$ for $48 \mathrm{~h}$. The authors showed that extraction in a medium of $\mathrm{SC}-\mathrm{CO}_{2}$ removes lipids from the tissue by $14 \%$ more efficiently than traditional extraction with $n$-hexane in a Soxhlet apparatus. The biocompatibility of the material was shown during the cultivation of mesenchymal stem cells isolated from human bone marrow on it. However, in this work, the authors did not determine the mechanical properties and immunogenicity of the formed matrices. A similar method including consecutive processing in a medium of $\mathrm{SC}-$ $\mathrm{CO}_{2}$, rinsing with a $3 \%$ solution of $\mathrm{H}_{2} \mathrm{O}_{2}$, processing in a medium of subcritical water, and final processing in $\mathrm{SC}-\mathrm{CO}_{2}$ was developed by a different group of authors for the formation of matrices on the basis of xenogeneic bone tissue [58].

Therefore, the method of decellularization in a medium of $\mathrm{SC}-\mathrm{CO}_{2}$ is to a greater extent appropriate for tissues that are not subjected to regular stresses because the high pressure accompanying the process of the treatment inevitably affects the structure and the mechanical properties of tissues.

In [8], the authors used a medium of $\mathrm{SC}-\mathrm{CO}_{2}$ for the formation of a decellularized adipose tissue extracellular matrix. Adipose tissue was treated for $3 \mathrm{~h}$ at $18 \mathrm{MPa}$ and $37^{\circ} \mathrm{C}$ with the addition of ethanol as the cosolvent. The developed material consisted of the extracellular matrix components and was free from lipids. A decellularized adipose tissue extracellular matrix can serve as a universal coating improving the adhesion of cells due to the presence of active components (collagen, laminin, elastin, fibronectin, and glycosaminoglycans). It was shown that such a coating intensifies the proliferation of human endothelial cells isolated from umbilical vein, human adipose tissue- 
derived mesenchymal stem cells, human monocytic leukemia cells, and immortalized human keratinocytes on a cultural plastic and does not induce the formation of a proinflammatory phenotype of macrophages.

Another field of application of an adipose tissue extracellular matrix is the modeling of breast cancer for the investigation of the action of anticancer drugs on cells under the conditions as close to the native conditions as possible [59]. The proposed technique of decellularization differs from the existing ones by the quickness and low cost. Traditional methods of decellularization of adipose tissue include several freezingthawing cycles, extraction of lipids with isopropanol, and enzymatic treatment $[59,60]$. The development of a technique for the preparation of an extracellular matrix from adipose tissue in an available and environmentally friendly way will promote the improvement of the methods of tissue engineering with the use of the autologous material.

Pericardium-the connective tissue surrounding the heart-has been successfully used in reconstructive surgery as an accessible source of an extracellular matrix for several decades. The interest in pericardium as a universal bioplastic material is determined by the attractive biomechanical and hemodynamic properties. The existing techniques of decellularization include the treatment by nonionic detergents (Triton X-100) [61, 62], 3-((3-chloroamidopropyl)dimethylammonio)-1-propanesulfonate (CHAPS) [63], ionic detergents (SDS) [64, 65], sodium deoxycholate [66], alkalis [67], and enzymes (a mixture of trypsin with EDTA) [68, 69]. However, the negative influence of the aforementioned techniques on the structure and composition of an extracellular matrix was shown. For example, the denaturating action of the detergents such as SDS and Triton X-100 on collagen of the extracellular matrix was found using staining by a fluorescently labeled collagen hybridizing peptide. Detergents such as CHAPS and sodium deoxycholate did not induce denaturation of collagen; however, they violated the structural organization of fibrils along with SDS and Triton X-100, which was confirmed via recording of the second harmonic signal and transmission electron microscopy [63]. It was also shown that the treatment of bovine pericardium tissue by Triton X-100 decreases the concentration of glycosaminoglycans by $\sim 62-66 \%$, and in an alkaline solution, by $\sim 88.6 \%$, at the initial concentration of $\sim 0.6 \mathrm{mg} / \mathrm{g}$ $[70,71]$. The processing in $\mathrm{SC}-\mathrm{CO}_{2}$ for $1 \mathrm{~h}$ at $35^{\circ} \mathrm{C}$ and $10 \mathrm{MPa}$ after decellularization by $1.25 \mathrm{M} \mathrm{NaOH}$ itself promoted fast washing out of the cellular components from the tissue [72]; here, the mechanical properties and structure of the material were comparable to the native tissue.

\section{CONCLUSIONS}

The results presented here allow the medium of $\mathrm{SC}-\mathrm{CO}_{2}$ to be considered as a universal tool for the development, formation, and modification of biomaterials and medical devices. The versatility of the technology consists in its potential application at different stages of the fabrication of a biomaterial including structuring, impregnation, and sterilization. The combination of several functions in one environmentally friendly process opens up new prospects for the development of tissue engineering.

\section{FUNDING}

This work was supported by the in-house grant from the Sechenov First Moscow State Medical University and Russian Science Foundation (grant no. 8-29-06056 MK for the part of the review devoted to the aspects of interaction of a medium of $\mathrm{SC}-\mathrm{CO}_{2}$ and materials and grant no. 18-3300982 мол for the part of the review devoted to the formation of three-dimensional structures and sterilization).

\section{REFERENCES}

1. A. Vashi, J. Werkmeister, T. Vuocolo, S. Elvin, and J. Ramshaw, J. Biomed. Mater. Res. A 100, 2239 (2012).

2. A. Barms, C. Oliveira, R. Reis, E. Lima, and A. Duarte, Int. J. Pharm. 495, 651 (2015).

3. A. Barms, S. Bmwne, C. Oliveira, E. Lima, A. Duarte, K. Heafy, and R. Reis, Int. J. Pharm. 513, 227 (2016).

4. Y. Seo, Y. Jung, and S. Kim, Acta Biomater. 67, 270 (2018).

5. P. Timashev, K. Bardakova, S. Churbanov, L. Krotova, A. Grigoriev, M. Novikov, S. Lakeev, V. Sevastianov, and V. Bagratashvili, Russ. J. Transplantol. Artif. Organs 18, 85 (2016).

6. M. Meyer, I. Prade, K. Leppchen-Frohlich, A. Felix, V. Herdegen, R. Haseneder, and J. U. Repke, J. Supercrit. Fluids 102, 32 (2015).

7. A. Bernhardt, M. Wehrl, V. Paul, T. Hochmuth, M. Schumacher, K. Schutz, and M. Gelinsky, PLoS One 10, e0129205 (2015).

8. J. Wang, V. Luo, V. Guneta, L. Li, S. Foo, Y. Dai, T. Tan, N. Tan, C. Choong, and M. Wong, Mater. Sci. Eng. C 75, 349 (2017).

9. J. Balestrini, A. Liu, A. Gard, J. Huie, K. Blatt, J. Schwan, L. Zhao, T. Broekelmann, R. Mecham, K. Wilcox, and L. Niklason, Tissue Eng., Part C 22, 260 (2016).

10. C. Garcia-Gonzalez, A. Concheiro, and S. AlvarezLorenzo, Bioconjug. Chem. 26, 1159 (2015).

11. A. Aguiar-Ricardo, V. Bonifacio, T. Casimim, and V. Correia, Philos. Trans., A 373, 20150009 (2015).

12. G. Porta, E. Reverchon, and N. Maffulli, Curr. Pharm. Des. 23, 3759 (2017).

13. A. Sikin and S. Rizvi, Recent Pat. Food Nutr. Agric. 3, 212 (2011). 
14. C. Potter, Y. Tian, G. Walker, C. McCoy, P. Hornsby, C. Donnelly, D. Jones, and G. Andrews, Mol. Pharm. 12, 1377 (2015).

15. E. Anderson, M. Noble, S. Garty, H. Ma, J. Bryers, T. Shen, and B. Ratner, Biomaterials 30, 5675 (2009).

16. M. Braga, M. Vaz Pato, H. Costa Silva, E. Ferreira, M. Gil, C. Duarte, and H. de Sousa, J. Supercrit. Fluids 44, 245 (2008).

17. A. Dias, M. Braga, I. Seabra, P. Ferreira, M. Gil, and H. de Sousa, Int. J. Pharm. 408, 9 (2011).

18. D. Pascoal, E. Cabral-Albuquerque, E. Velozo, H. de Sousa, S. Vieira de Melo, and M. Braga, J. Supercrit. Fluids 129, 106 (2017).

19. A. Bouledjouidja, Y. Masmoudi, Y. Li, W. He, and E. Badens, J. Cataract. Refract. Surg. 43, 1343 (2017).

20. S. L. Ma, Z. W. Lu, Y. T. Wu, and Z. B. Zhang, J. Supercrit. Fluids 54, 129 (2010).

21. R. Weinstein, K. Muske, S. Martin, and D. Schaeber, Ind. Eng. Chem. Res. 49, 7281 (2010).

22. I. Cabezas, L. Fernandez, V. Mazarm, R. Gracia, I. Lucas, and A. Rodriguez, J. Supercrit. Fluids 63, 155 (2013).

23. S. Duarte, J. Supercrit. Fluids 1, 165 (2010).

24. M. Fanovich, J. Ivanovic, D. Misic, M. Alvarez, P. Jaeger, I. Zizovic, and R. Eggers, J. Supercrit. Fluids 78, 42 (2013). https://doi.org/10.1016/j.supflu.2013.03.017

25. L. Hardelin, A. Strom, E. di Maio, S. Iannace, and A. Larsson, Carbohydr. Polym. 181, 442 (2018).

26. J. Tainio, K. Paakinaho, K. Ahola, M. Hannula, J. Hyttinen, M. Kellomaki, and J. Massera, Materials (Basel) 10, E1274 (2017).

27. M. Salarian, W. Xu, Z. Wang, T. Sham, and P. Charpentier, ACS Appl. Mater. Interfaces 6, 16918 (2014).

28. Y. Zhang, J. Wang, Y. Ma, V. Han, X. Niu, J. Liu, L. Gao, J. Wang, X. Zhai, K. Chu, and L. Yang, Biomed. Mater. Eng. 29, 67 (2018).

29. E. N. Antonov, S. A. Bochkova, and A. V. Popova, Russ. J. Phys. Chem. B 5, 1253 (2011).

30. E. N. Antonov, A. V. Popova, I. I. Selezneva, V. V. Troflmov, A. Yu. Fedotov, and A. S. Fomin, Russ. J. Phys. Chem. B 5, 1189 (2011).

31. L. Diaz-Gomez, S. Garcia-Gonzalez, J. Wang, F. Yang, S. Aznar-Cervantes, J. Cenis, R. Reyes, A. Delgado, C. Evora, A. Concheiro, and C. AlvarezLorenzo, Int. J. Pharm. 527, 115 (2017).

32. A. Vega-Gonzalez, P. Subra-Paternault, A. LopezPeriago, C. Garcia-Gonzalez, and C. Domingo, Eur. Polym. J. 44, 1081 (2008).

33. P. S. Timashev, N. N. Vorobieva, A. A. Akovantseva, N. V. Minaev, Yu. A. Piskun, S. V. Kostjuk, I. I. Selezneva, I. V. Vasilenko, O. L. Zakharkina, N. Yu. Ignatieva, R. K. Chailakhyan, V. V. Lunin, and V. N. Bagratashvili, Russ. J. Phys. Chem. B 11, 1095 (2017).

34. R. Butler, I. Hopkinson, and A. Cooper, J. Am. Chem. Soc. 125, 14473 (2003).

35. Z. Dai, J. Ronholm, Y. Tian, V. Sethi, and X. Cao, J. Tissue Eng. 7, 2041731416648810 (2016).

36. N. Norulaini, A. Ahmad, M. Omar, A. Banana, M. Sarker, and K. Mohd, Separ. Purif. Technol. 60, 272 (2008).
37. Q. Qiu, P. Leamy, J. Brittingham, J. Pomerleau, N. Kabaria, and J. Connor, J. Biomed. Mater. Res. B 91, 572 (2009).

38. T. Baldini, K. Caperton, M. Hawkins, and E. McCarty, Knee Surg. Sports. Traumatol. Arthrosc. 24, 3971 (2016).

39. D. Bui, V. Lovric, R. Oliver, N. Bertollo, D. Broe, and W. Walsh, Cell. Tissue Bank 3, 467 (2015).

40. A. Yanke, R. Bell, A. Lee, R. Kang, R. Mather, E. Shewman, V. Wang, and B. Bach, Am. J. Sports. Med. 41, 835 (2013).

41. N. Russell, A. Rives, M. Pelletier, W. Bruce, and W. Walsh, Cell. Tissue Bank 14, 231 (2013).

42. N. Russell, A. Rives, M. Pelletier, T. Wang, and W. Walsh, Cell. Tissue Bank 16, 109 (2015).

43. G. van de Pol, F. Bonar, L. Salmon, J. Roe, and L. Pinczewski, Arthroscopy 34, 706 (2018).

44. R. S. Hennessy, S. Jana, V. Teffi, M. Helder, M. Young, R. R. Hennessy, N. Stoyles, and A. Lerman, JACC Basic Transl. Sci. 2, 71 (2017).

45. R. S. Hennessy, J. Go, R. Hennessy, V. Teffi, S. Jana, N. Stoyles, M. Al-Hijji, J. Thaden, S. Pislaru, R. Simari, J. Stulak, M. Young, and A. Lerman, PLoS One 12, e0181614 (2017).

46. W. Stoppel, J. White, S. Horava, A. Henry, S. Roberts, and S. Bhatia, J. Biomed. Mater. Res. B 102, 877 (2014).

47. H. Yu, G. Cauchois, J. F. Schmitt, N. Louvet, J. I. Six, Y. Chen, R. Rahouadj, and S. Huselstein, J. Mech. Behav. Biomed. Mater. 68, 134 (2017).

48. A. V. Suslov, I. N. Suslova, A. A. Murzin, and D. N. Shaflkov, Russ. J. Phys. Chem. B 8, 1038 (2014).

49. A. V. Suslov and I. N. Suslova, Russ. J. Phys. Chem. B 11, 1109 (2017).

50. P. Crapo, T. Gilbert, and S. Badylak, Biomaterials 32, 3233 (2011).

51. K. Sawada, D. Terada, T. Yamaoka, S. Kitamura, and T. Fujisato, J. Chem. Technol. Biotechnol. 83, 943 (2008).

52. N. Sabirzyanov, A. Win, A. Akhunov, and A. Gumerov, High Temp. 40, 203 (2002).

53. S. Guler, V. Asian, P. Hosseinian, and H. Aydin, Tissue Eng., Part C 23, 540 (2017).

54. Y. Hashimoto, S. Funamoto, S. Sasaki, T. Honda, S. Hattori, K. Nam, T. Kimura, M. Mochizuki, T. Fujisato, H. Kobayashi, and A. Kishida, Biomaterials 31, 3941 (2010).

55. Y. Hashimoto, S. Hattori, S. Sasaki, T. Honda, T. Kimura, S. Funamoto, H. Kobayashi, and A. Kishida, Sci. Rep. 6, 27734 (2016).

56. Y. Hashimoto, S. Funamoto, S. Sasaki, J. Negishi, T. Honda, S. Hattori, K. Nam, T. Kimura, M. Mochizuki, H. Kobayashi, and A. Kishida, PLoS One 10, e0131989 (2015).

57. D. V. Smolentsev, M. V. Gurin, A. A. Venediktov, S. V. Evdokimov, and R. A. Fadeev, Russ. J. Phys. Chem. B 11, 1283 (2017).

58. D. Yu. Zalepugin, V. V. Zaitzev, N. A. Tilkunova, I. V. Chemyshova, I. I. Selezneva, Yu. A. Nikonova, and M. I. Vlasov, Russ. J. Phys. Chem. B 9, 1005 (2015). 
59. L. Flynn, Biomaterials 31, 4715 (2010).

60. V. Brown, J. Freund, L. Han, J. Rubin, J. Reing, E. Jeffries, M. Wolf, S. Tottey, C. Barnes, B. Ratner, and S. Badylak, Tissue Eng., Part C 17, 411 (2011).

61. V. Mendoza-Novelo, L. Castellano, R. Padilla-Miranda, M. Lona-Ramos, P. Cuellar-Mata, A. Vega-Gonzalez, M. Murguia-Perez, J. Mata-Mata, and E. Avila, J. Biomed. Mater. Res. A 104, 2810 (2016).

62. M. Ariganello, R. Labow, and J. Lee, J. Biomed. Mater. Res. A 93, 280 (2010).

63. J. Hwang, V. San, N. Turner, L. White, D. Faulk, S. Badylak, Y. Li, and S. Yu, Acta Biomater. 53, 268 (2017).

64. S. Seif-Naraghi, M. Salvatore, P. Schup-Magoffin, D. Hu, and K. Christman, Tissue Eng., Part A 16, 2017 (2010).

65. S. Park, S. Kim, H. Lim, C. Lim, and Y. Kim, Korean J. Thorac Cardiovasc. Surg. 46, 1 (2013).
66. H. Perme, A. Sharma, N. Kumar, H. Singh, R. Dewangan, and K. Maiti, Ind. J. Animal Sci. 79, 658 (2009).

67. W. Sun, H. Xu, M. Sandor, and J. Lombardi, J. Tissue Eng. 4, 2041731413505305 (2013).

68. E. Pagoulatou, I. Triantaphyllidou, D. Vynios, D. Papachristou, E. Koletsis, D. Deligianni, and D. Mavrilas, J. Mater. Sci. Mater. Med. 23, 1387 (2012).

69. J. Hulsmann, K. Grun, S. ElAmouri, M. Barth, K. Hornung, C. Holzjufi, A. Lichtenberg, and P. Akhyari, Xenotransplantation 19, 286 (2012).

70. X. Dong, X. Wei, W. Yi, C. Gu, X. Kang, Y. Liu, Q. Li, and D. Yi, J. Mater. Sci. Mater. Med. 20, 2327 (2009).

71. V. Mendoza-Novelo, E. Avila, J. Cauich-Rodriguez, E. Jorge-Herrero, F. Rojo, G. Guinea, and J. L. MataMata, Acta Biomater. 7, 1241 (2011).

72. F. Halfwerk, J. Rouwkema, J. Gossen, and J. Grandjean, J. Mech. Behav. Biomed. Mater. 77, 400 (2018).

Translated by E. Boltukhina 